\title{
THE ENTREPRENEURIAL DECISION MAKING: USE OF EFFECTUATION AND RELATION WITH PERCEIVED FINANCIAL PERFORMANCEAND INNOVATION IN THE FIRM
}

\author{
Subeika Rizvi \\ Subeika Rizvi is an Assistant Professor at SZABIST, Karachi, \\ Shahid Querishi \\ Assistant Professor at IBA, Karachi \\ ErumZaidi \\ Assistant Professor, IoBM \\ Muhammad Ali Saeed \\ Assistant Professor, Bahira University
}

\begin{abstract}
During the start of the venture entrepreneurs rely on a number of techniques and strategies to make decisions. Effectuation and causation are important modes of this decision making process. The theory on effectuation is advancing from an early to a mature phase globally thus it's important to understand its dimensions and their influence on the firm's performance. This study explores the use of this effectual logic in micro and small firms operating in Pakistan and its influence on the financial performance and level of innovation in these firms. Although few researches have been focused on the antecedents and dependents of effectuation but none have arrived at a consensus on the appropriate variables. In Pakistan, as it's a relatively new concept although being applied, there is all the more need to assess the nature of effect these variables could have on some of the important outcomes of the firm. This research contributes to existing literature by providing relationship of effectuation with, another important, variable of innovation in the firm.

In this empirical study, a sample of 166 micro and small firm entrepreneurs was used all operating businesses within Pakistan. A survey, through a questionnaire, was conducted using snowball sampling. Findings indicate that use of effectuation is positively correlated with both higher perceived financial performance and level of innovation employed in the firms. Also not all effectual constructs have uniform influence on the variables which explains the formative nature of the logic of effectuation. A few implications of this study and future research areas have also been identified.
\end{abstract}

Keywords: Effectuation, firm performance, innovation

Jel Classification: L26, LO32, L040

*The material presented by the author does not necessarily portray the view point of the editors and the management of the Ilma University - Formerly IBT 


\section{INTRODUCTION}

The entrepreneurs are not a homogeneous group and differ in their personality traits, orientation and eventually the way they process information and make decisions. At the heart of the entrepreneurial process lies the decision making .The decision making is more concerned with opportunity identification (Shane \& Venkataraman, 2000) and leads to differences among entrepreneurs. An inherent property of this decision process is uncertainty (and risk), which is mainly due to novelty of situation at hand (Sarasvathy et.al, 2003). When faced with varying uncertainties, entrepreneurs employ different tactics to untangle the issue and it is this entrepreneurial logic applied that has been the focus of study by many researchers to unravel the strategy applied that ultimately aims to lead towards success. Ever since, research on entrepreneurial decision making is growing especially in the face of uncertainty (Sarasvathy, 2009; Haynie \& Gustavsson, 2011; Johansson \& McKliev, 2012). Most of this research has been conducted with respect to the approach adopted for decision making where causation and effectuation have been seen as alternate approaches for the venture creation and performance (Sarasvathy, 2001; Smolka,Verheul \& Lamp, 2015; McKelvie \& Chandler 2011).

Effectuation and causation are two important modes of entrepreneurial decision making or logic. Causation has been described as a decision making process that relies on planning and analysis for the exploration of the latent markets along with planned strategy approaches (Brews \& Hunt, 1999). Causal reasoning focuses on what can be done given pre-determined goals using the logic of prediction. This process of causation is associated with planned strategy approaches that calls for business planning and competitive analysis focused on maximizing financial returns (Sarasvathy, 2001; Dew, Read\& Sarasvathy, 2006; McKelvie \& Chandler 2011). Causation is a more linear approach driven by goals and a more analytic approach taught in most business schools today (Johansson \& McKliev, 2012. In contrast, the process of effectuation is in consistence with more non-predictive, emergent techniques (Sarasvathy, 2001; Chandler et,al, 2001).Instead of trying to make the nascent firm robust for the future events through meticulous business planning and predictive techniques, the focus here is on control strategies which is based on flexibility, using all disposable resources and making all desired stakeholder commitments for the discovery of new markets and products (Sarasvathy, 2001; 2008). Numerous studies have been conducted to build on the effectuation model proposed by Sarasvathy (2001) with some focusing on angel investors (Wiltbank,Read,Dew \& Sarasvathy, 2009), twitter accounts (Fisher 7 Reuber, 2011) and most of these show a positive relationship between effectuation and performance (Perry, Chandler \& Markova, 2012).

The depenedent variables to measure the venture performance vary greatly from growth in profit, sales, cash flow, employees, return on investment/capital/assets, market shares, earning per share etc (Murphy, Trailer, \& Hill, 1996). Due to this it is harder to compare the results across different sectors, industries and even the studies conducted. The study by Murphy, Trailer \& Hill (1996) also found that while a certain given variable may affect performance positively, it may not have the same or even at times the negative impact on some other measure of performance. Hence the conclusions of the study need to be limited to only the measured performance variables.In one of his studies, Davidsson (2004) makes a very strong case for job creation as being one of the dependent variables for performance, due to its important role played in policy making, research and media and the implications on the overall society. The outcome, as measured by the dependent variable, should be from a 
different point in time and source than the explaining variable to avoid any causality and variance problems. Hence we can summarize that there is no standard way of operationalization for the dependent variable and all existing ones cover different aspects of performance. The financial variables are always more reliable due to the objective nature and the weightage given to them by most of the entrepreneurs. After all it all boils down to the financial numbers to gauge the performance and comparison across industries.

The other important variable in this study is level of innovation and its dependence on the use of effectual logic. Entrepreneurial Innovation is the process of creating value for consumers through a novel idea with a sustainable and scalable model.Innovation often fosters creation of a sustainable market through the introduction of improved product/service or process. Technological Innovation is considered as the introduction of new product/service based on new technology (Carayannis et. al, 2015). Dynamic or turbulent environment is an important push-and-pull force for adoption of innovation in SMEs (Maes \& Sels, 2014).Innovation is a significant factor interconnected to venture strategy and subsequent results. Effectuation appears to be helpful to be used in unstable situations for the ventures dealing with the higher degrees of uncertainty where predictive tools/strategies cannot be used (Garonne et al. 2010). As the small ventures possess very limited resources; hence they emphasis on creative and innovative use of those available resources including existing technologies, competencies and relationship with key people and organizations (Hans Berends et al. 2014).

The relationship between use of effectuation and performance in the firms is still blur and lack of evidence and guidance on measuring the relevant performance outcomes. There has been no study so far to gauge the level of innovation in the firm in relation to the use of effectual logic. This study focuses on the different measures of performance and their relationship with the 4 sub components of effectuation (affordable loss, flexibility, experimentation and pre commitments) as outlined by Chandler et al. (2009). The research aims to add to the existing literature by providing the empirical evidence to this relationship of effectual logic, performance and level of innovation in the new ventures.

Ever since Sarasvathy(2001) work on effectuation many researchers have added to the stream of knowledge but most of this work has been focused on behavioral and cognitive skills of the entrepreneur (Politis \& Gabrielsson, 2006; Dew et al., 2009). The antecedents of effectuation have been studied but the consequences and outcomes are still blurred. The relationship between effectual and causal thinking is also problematic as few studies suggest they are inverse of each other (Dew et al., 2009; Read \& Sarasvathy, 2005) while others suggest they complement each other and can be used simultaneously (Politis \& Gabrielsson, 2006; Smolka,Verheul \& Lamp, 2015). The understanding of the effectual constructs is very important along with their effect on the venture and also the interrelation between these sub components. In order to integrate this new entrepreneurial thinking in the pedagogy, especially in Pakistan where its relatively in nascent stages, it's important for us to understand the factors contributing to the success or failure of some of the startups by the students who have mostly been exposed to causal decision making techniques. Such studies could not be found in context of developing countries, like Pakistan, where the uncertainty in environment is high and calls for more effectual thinking (Sarasvathy, 2001).

The concept of effectual logic is still very new in Pakistan where its limited to only entrepreneurial education in selective institutes. Ever since Sarasvathy (2001) proposed the effectuation model on entrepreneurial decision making many researches have been conducted worldwide on its antecedents as well as consequences on the new ventures. In Pakistan entrepreneurship is taught as a course in most Business Schools but mostly on the causal model focused on a goal oriented, planned approach. Effectuation is slowly being incorporated in the curriculum as awareness is growing but its consequences are yet to be 
studied. Internationally, all the research work has been focused on the use of this model in context of small and medium or large firms while study on micro or student ventures is still missing. Hence this study takes the first step in studying the effectual logic applied in the micro and small ventures and its impact on firm perceived financial performance and level of innovation. This would be the first indigenous study of its kind to apply the effectuation constructs and their relationship with firm performance and innovation in ventures in Pakistan which is very beneficial for the startups that face the most uncertainty and vulnerability in their survival.

The use of effectuation decision making is hypothesized to be positively associated with firm performance, to be measured in financial terms like sales, profit, cash flow and ROI (return on investment). This is drawn from the literature review and some major work on effectuation and performance by McKelvie et al (2013), Smolka, Verheul \& Lamp (2015). As drawn from most of the literature by Sarasvathy $(1998 ; 2001 ; 2002)$, effectuation leads to greater flexibility and capacity to experiment with various options that leads to greater innovation as innovation calls for these characteristics only. Hence it's also hypothesized that effectual logic should lead to greater innovation in the entrepreneurial ventures that use it more often.

Fig 1: Conceptual Model of effectuation outcome Effectuation

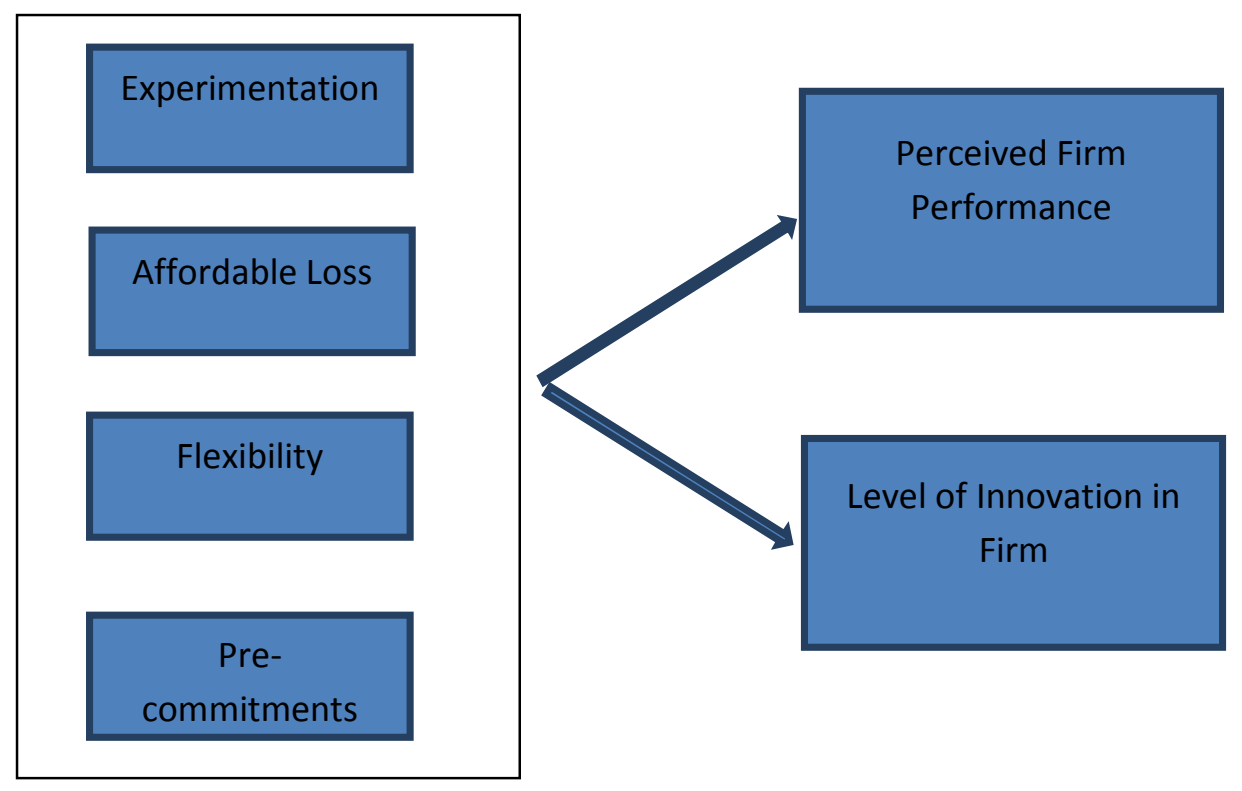

Dependent Variables: The performance and the innovation in the firms are the dependent variables for this study. Performance has been taken as a multi-faceted component measuring the time taken for achievement of milestones and also relative to the competitors. Achieving sales and profit faster is an important milestone for the firms (Eisenhardt, \& Lyman, 1990; Davidsson \& Honig, 2002) and hence used to gauge the performance. Those with effectual logic are able to deal and reach with the market and capitalize on the opportunities faster and hence time is an important measure in performance. Thus effectuation should be positively related to performance. The innovation has been measured in terms of products and processes and the introduction of variations and new processes is an indication of level of innovation. The use of effectuation is related to flexibility and quicker, prompt response to market contingencies and hence it's argued that it should be positively related to innovation level in the firm. 
Independent Variable: The independent variable is effectuation which is captured using multiple items as validated in the literature. Chandler et al.'s (2011) operationalization of sub components of effectuation has been used in this study.

Control Variables: This study has used 3 control variables: age, gender and the educational background of the entrepreneur.

\section{RESEARCH METHODOLOGY}

The study is based on the post positivist approach as it aims to identify and develop a relationship between the effectual logic of entrepreneurial decision making the venture performance therefore the truth will be inferred by verification or falsification of the considered hypothesis through the process of deduction. A deductive approach will be taken to test the effectuation theory and its impact on the performance and innovation of the firms using a mono method of survey through a questionnaire. The empirical testing of the hypothesis calls for a quantitative design which will be used in this study. The quantitative method will allow us to test and verify the establish hypothesis and allows for a logical approach with a set of measurement (Reichardt \& Cook, 1979).A cross sectional data will be used to test the given hypothesis.

The population for this study is all the small and medium enterprises operating in Karachi; Pakistan. The sample has been drawn using the sample table in Saunders (2007), with a 95\% level of certainty and $10 \%$ margin of error which gave a sample size of 96 . As the micro businesses are much more than small ones in Pakistan the sample size will be split 60:40(this is based on estimate given by Akhuwat Foundation) among the micro and small respectively. The sample size will hence be: Micro business: 58, Small business: 38 . The snow ball sampling has been used in the study as no formal directory or statistics is available for these entrepreneurs and could only be reached through contacts. Moreover, as age of the firm is of interest in the study, the micro firms operating for 1-2 years having less than 10 employees and small firms operating for 3-5 years having less than 50 employees have been selected for the study.

The data has been collected through a survey questionnaire which has been based on extensive review of literature. The questionnaire is developed after many stages of brainstorming, amending, reviewing by the researcher and the supervisor. The questionnaire has been divided into different parts with the introductory paragraph followed by the screening questions. The measures of effectuation, firm performance and level of innovation in the firm have then been measured. All measures are based on 1 to 5 Likert scale. The Likert scale was incorporated so as to rate the importance of each factor relative to the others. The scales to measure effectual logic are derived from study of Chandler et al (2011) along with the sub components of effectuation. The firm performance and innovation scales are based on study by McKelvie, DeTienne \& Chandler(2013).

The face validity of the questionnaire has been done through expert entrepreneurs. The scale used by Chandler et al (2011) have been validated by the authors using exploratory and confirmatory analysis and was measured on the internal consistency with the Cronbach Alpha of 0.78 which shows sufficient reliability for purpose of research ((Nunnally and Bernstein, 1994). The analysis conducted also established content, predictive and constructs validity in the study. The four dimensions of effectuation used are: experimentation, affordable loss and pre commitments. The survey questionnaire is checked for reliability using a sample of 40 entrepreneurs through the Cronbach Alpha. 
The research methodology applied in this research is post-positivism which concentrates on falsification. If the theory is able to falsify the hypothesis, then we should be able to support the proposed theory. The alternative hypothesis for this study is:

H1: A positive relationship exists between an entrepreneur's use of effectuation and the venture perceived financial performance

H1a. A positive relationship exists between an entrepreneur's use of experimentation and the venture perceived financial performance

H1b. A positive relationship exists between an entrepreneur's use of affordable loss and the venture perceived financial performance

H1c. A positive relationship exists between an entrepreneur's use of flexibility and the venture perceived financial performance

H1d. A positive relationship exists between an entrepreneur's use of pre-commitments and the venture perceived financial performance

H2: A positive relationship exists between an entrepreneur's use of effectuation and the level of innovation used in the firm.

H2a. A positive relationship exists between an entrepreneur's use of experimentation and the level of innovation used in the firm.

H2b. A positive relationship exists between an entrepreneur's use of affordable loss and the level of innovation used in the firm.

H2c. A positive relationship exists between an entrepreneur's use of flexibility and the level of innovation used in the firm.

H2d. A positive relationship exists between an entrepreneur's use of pre-commitments and the level of innovation used in the firm.

H3: The use of effectuation influences the perceived financial performance of the firm

H4: The use of effectuation influences the level of innovation in the firm

H3: The use of effectuation varies with the age of the firm.

\section{DATA ANALYSIS AND FINDINGS}

The data has been collected through questionnaires and has been coded, edited and keyed into SPSS software. The frequency tables have been generated to access the age and gender of respondents and it shows that the ratio of firms is 60:40 between the micro and small firms and about $70 \%$ male and $28 \%$ female entrepreneurs responded. Majority of respondents fall in 25-34 age groups. A total of 167 responses were gathered through online questionnaire and circulating through contacts.

Validity is the extent to which the scale measures the concept of interest. Hair et al. (2010) suggest that for samples greater than 85 but smaller than 100 factor loadings greater than 0.6 are significant. Exploratory factor analysis assists us investigate the underlying structure of a set of variables and data reduction (Hair et al. 2010). All of the constructs have factor loadings greater than 0.6 which are considered to be significant, given the sample size in the study. Reliability is a measure for the stability and consistency of the operationalized elements in the study. The scale used in this study has been adopted by Chandler et al. (2009) where the effectuation has been taken as a formative construct comprising of: experimentation, affordable loss, flexibility and pre commitments. There are questions 
against each construct and reliability of the dimensions within each construct as measured by Cronbach Alpha. All of the values are above 0.6 and around 0.8 which is a high reliability standard (Hair et al., 2006; Nunally, 1967; Sekaran and Bougie, 2010). The overall reliability of the instrument is also close to 0.7 which is considered to be reliable.

The correlation test between the effectuation constructs and perceived financial performance indicated a positive relationship with total effectuation correlated with a highly significant correlation of 0.221 . It was observed from the correlation test of the 4 constructs with financial performance that the strongest positive relationship with performance is of the use of pre-commitments and experimentation. All of these are significant with a $p$ value less than 0.05 . Only affordable loss had a significant negative relationship of -0.187 .

The variable of innovation was also measured on 5-point Likert Scale and the questions were then added and average taken for the total innovation. The use of effectuation has been measured as a formative construct of the 4 dimensions stated above. A strong positive relationship exists between the two variables with a Person coefficient of 0.429 signifying a high strength and significance at the 0.01 level. The association between the effectuation elements and innovation is also measured using correlation matrix in SPSS. Experimentation is positively related with a strong coefficient of 0.494 while flexibility and pre-commitments also have a strong correlation of 0.496 and 0.515 respectively. These all are statistically significant at 0.01 level. This leads to the acceptance of $\mathrm{H} 2$ along with $\mathrm{H} 2 \mathrm{a}, \mathrm{c}$ and $\mathrm{d}$. The element of affordable loss, however, has a weak correlation of 0.043 with a $\mathrm{p}$ value of greater than 0.05 and hence we accept the alternate hypothesis and conclude that affordable loss does not have a positive correlation with innovation.

The impact of effectuation constructs on financial performance was measured through the regression analysis. The mean of each of the construct was computed to arrive at the total of each dimension for effectuation that though the overall model of association is relatively strong with adj R2 of 0.404 and hence all four dimensions of effectuation account for $40.04 \%$ variation in financial performance. The greatest influence is of the use of pre-commitment with $\beta$ of 0.299 and significant. All other dimensions have significant and positive influence except affordable loss which has a negative significant influence with high t value of -3.1 . The impact of the constructs on level of innovation was also tested through the regression model where we had a $42 \%$ support for this model with a predictive value denoted by adj R2 of 0.416 .The greatest influence, here, was of flexibility with a significant $\beta$ of 0.312 while again affordable loss had no significant influence on innovation with $t$ value less than 2 at 0.613. Overall the model was significant with a $\mathrm{p}$ value less than 0.05

A t-test for independent samples was used to assess whether the micro and small firms differ in their use of effectuation. It was observed that the Leven's test was 3.25 and not significant at 0.073 and hence we may conclude that the use of effectuation doesn't differ with the age of the firm. 
Table 1: Summary of findings

\begin{tabular}{|c|c|c|c|}
\hline Research Objective & Alternate Hypothesis & Analysis & Conclusion \\
\hline $\begin{array}{l}\text { To examine the relationship } \\
\text { between the effectual } \\
\text { constructs and the perceived } \\
\text { financial performance of the } \\
\text { firms }\end{array}$ & $\begin{array}{l}\text { H1: A positive relationship exists } \\
\text { between an entrepreneur's use of } \\
\text { effectuation and the venture } \\
\text { perceived financial performance } \\
\text { H1a. A positive relationship exists } \\
\text { between an entrepreneur's use of } \\
\text { experimentation and the venture } \\
\text { perceived financial performance } \\
\text { H1b. A positive relationship exists } \\
\text { between an entrepreneur's use of } \\
\text { affordable loss and the venture } \\
\text { perceived financial performance } \\
\text { H1c. A positive relationship exists } \\
\text { between an entrepreneur's use of } \\
\text { flexibility and the venture perceived } \\
\text { financial performance } \\
\text { H1d. A positive relationship exists } \\
\text { between an entrepreneur's use of } \\
\text { pre-commitments and the venture } \\
\text { perceived financial performance }\end{array}$ & $\begin{array}{l}\text { Correlation } \\
\text { r=0.221, sig: } 000 \\
\text { Correlation } \\
\text { r=0.415, sig: } 000 \\
\text { Correlation } \\
\text { r=-0.187, } \\
\text { sig: } 0.016 \\
\text { Correlation } \\
\text { r=0.403, sig: } 000 \\
\text { Correlation } \\
\text { r=0.564, sig: } 000\end{array}$ & $\begin{array}{l}\text { Accept H1a } \\
\text { Reject H1b } \\
\text { Accept H1c } \\
\text { Accept H1d }\end{array}$ \\
\hline $\begin{array}{l}\text { To find the relationship } \\
\text { between the use of effectual } \\
\text { logic and innovation in the } \\
\text { firm. }\end{array}$ & $\begin{array}{l}\text { H2:A positive relationship exists } \\
\text { between an entrepreneur's use of } \\
\text { effectuation and the level of } \\
\text { innovation used in the firm. } \\
\text { H2a. A positive relationship exists } \\
\text { between an entrepreneur's use of } \\
\text { experimentation and the level of } \\
\text { innovation used in the firm. } \\
\text { H2b. A positive relationship exists } \\
\text { between an entrepreneur's use of } \\
\text { affordable loss and the level of } \\
\text { innovation used in the firm. } \\
\text { H2c. A positive relationship exists } \\
\text { between an entrepreneur's use of } \\
\text { flexibility and the level of } \\
\text { innovation used in the firm } \\
\text { H2d. A positive relationship exists } \\
\text { between an entrepreneur's use of } \\
\text { pre-commitments and the level of } \\
\text { innovation used in the firm }\end{array}$ &  & $\begin{array}{l}\text { Accept H1 } \\
\text { Accept H1a } \\
\text { Reject H1b } \\
\text { Accept H1c } \\
\text { Accept H1d }\end{array}$ \\
\hline $\begin{array}{l}\text { To determine whether the use } \\
\text { of effectuation affects the } \\
\text { perceived financial } \\
\text { performance of the firms }\end{array}$ & $\begin{array}{l}\text { H3: The use of effectuation } \\
\text { influences the perceived financial } \\
\text { performance of the firm }\end{array}$ & $\begin{array}{l}\text { Regression } \\
\text { analysis } \\
\text { Adjusted } \\
\text { R2=0.404,Beta } \\
\text { coefficients are } \\
\text { significant }\end{array}$ & Accept H3 \\
\hline $\begin{array}{l}\text { To determine whether the use } \\
\text { of effectuation affects the level } \\
\text { of innovation in the firms }\end{array}$ & $\begin{array}{l}\text { H4: The use of effectuation } \\
\text { influences the level of innovation in } \\
\text { the firm }\end{array}$ & $\begin{array}{l}\text { Regression } \\
\text { analysis } \\
\text { Adjusted } \\
\text { R2=0.416, Beta } \\
\text { coefficients are } \\
\text { significant }\end{array}$ & Accept H4 \\
\hline $\begin{array}{l}\text { To determine whether the use } \\
\text { of effectuation varies with the } \\
\text { age of the firm. }\end{array}$ & $\begin{array}{l}\text { H5: The use of effectuation varies } \\
\text { with the age of the firm. }\end{array}$ & $\begin{array}{l}\text { t-test for } \\
\text { independent } \\
\text { samples } \\
{[F=.3 .25,} \\
p>0.05 ; \quad t=- \\
0.36, p>0.05]\end{array}$ & Reject H5 \\
\hline
\end{tabular}




\section{DISCUSSION}

The data analysis shows that most of the findings are consistent with the literature review. As suggested by Sarasvathy (2001), effectuation has been studied as a formative construct made up of experimentation, flexibility, affordable loss and pre commitments. This is indicative from the mixed results of each of the construct on the performance and innovation applied in the firms. There have been mixed results showing that effectuation doesn't uniformly affects the firms, rather through the combined application of its constructs. It was found that use of effectuation does lead to higher financial performance especially while applying the principles of flexibility and pre- commitments. It is important to note that affordable loss is a negative predictor of perceived financial performance which was also found in the study of McKelvie, DeTienne and Chandler (2013).These mix of findings provide important insight into the impact of effectuation. It appears that only certain components of effectuation, when applied, help to drive performance while other has a opposite role to play. This further reinforces that effectuation is a multi-faceted construct where all components have different roles to play (Sarasvathy, 2001; Smolka,Verheul \& Lamp, 2015; McKelvie \& Chandler 2011). The use of pre-commitment has emerged as the strongest predictor of financial performance which is in line with the study of Stuart Read et al. (2008) and Heydenrych (2013). This can be explained through the "crazy quilt" principle of Sarasvathy (1998) where the new entrepreneurs develop strategic alliances and partnerships with various stakeholders that jointly shape the outcome of the business. In doing so, the uncertainty is reduced by spreading out the risk among the partners and with lower risk the expectation of a better performance increases. Also most of the respondents were relatively new entrants with majority having experience of 1-3 years into the business. During these early times of startup, firms face higher levels of uncertainty, as opposed to the established firms, and usually enter the market with limited resources. As discussed by Mthanti (2012), under such conditions strategic partnerships help diversify such uncertainties and provide more avenues for diversification. This can also be supported by the element of experimentation in effectuation, which has also been found to be positively related to performance. Experimentation allows the trial and error which further aids in diversification and reducing uncertainty. Hence a trial and error approach as opposed to planned, goal oriented approach to diversification helps in reducing the variability in the business and sharing the same with strategic partners. Also effectual partnerships help increase the knowledge, resources and information available to the new ventures (Sarasvathy \& Dew, 2005). This is also enhanced by the use of flexibility which facilitates the decision making for such diversifications and help cope with the un predictable factors to the make the required changes as necessary for achieving higher performance (Loch, Solt, \& Bailey, 2008). This can be seen by the positive impact of the use of flexibility in financial performance also shown by Stuart Read et al. (2008).

The findings regarding affordable loss are in contradiction to those predicted by Brettel et al., (2012), Chandler et al.(2011), Wiltbank et al. (2009). This study found negative relationship of affordable loss application and financial outcome. While operationalizing the affordable loss construct, the focus is on the financial losses that could be limited by the entrepreneur as compared to what he can bear. It seems that entrepreneurs who are less risk averse experience greater financial performance as compared to others. This can also be explained by the sample of the study which constitutes young firms that go through survival issues in face of competition which calls for taking on more risk and focus on increasing the upside potential as opposed to minimize losses. Those with an effectual approach of affordable loss during the early years, experience less profitable outcomes. Despite the fact that no support was found for affordable loss for both performance and innovation we cannot delete it as a construct of 
effectuation. According to MacKenzie et al., (2005) in the formative constructs the lower order measures shape the higher order ones due to the causal relationship present. Also the constructs have been determined by Sarasvathy (2001) through theoretical argument where the dimensions cannot be changed.

The impact of effectuation constructs on level of innovation applied in terms of product and service also has some interesting findings, most correlating with literature above. Innovation has always been considered as an important factor in determining the outcomes of a firm with the major antecedent being the decision making of entrepreneur. Effectuation, as a new theory, on the canvas of decision making seems to be conducive for innovative firms with high degree of uncertainty where predictive strategies cannot be used (Hydenrych, 2013). The findings also show a positive relationship between the use of effectuation and innovation level in the firm with flexibility and pre commitment as the strongest predictor and affordable loss having no impact. Interestingly, a positive relation is also observed between innovation and financial performance which means that applying innovative techniques does lead to better outcomes for the firm (Davidsson et al, 2010). The creative and innovative use of available resources calls for flexibility along with relationships with key people and organizations. Differentiation which is mainly due to trial and error or experimentation leads to greater performance in the firms and also maximizes their return by exploring new markets (Bradley et al., 2012). Again minimizing losses means taking on less risky ventures which could hamper creativity and innovation and this could explain the low score with affordable loss. Also the sample mainly constitutes of micro and small firms with limited resources and hence they focus more on innovative use of the available resources (Hans Berends et al. 2014). Such small firms are more open to changes and new ideas than bigger firms and use greater effectuation as compared to mature firms, a concept posit by Sarasvathy (2001) as well.

The use of effectuation by micro and small firms has been discussed by Sarasvathy (2001) as well whereas the firms grow bigger its orientation towards planned, casual approach increases. This is not seen in our study where both micro and small firms, new and experienced seem to employ same level of effectual logic. This could be due to the higher level of uncertainty in the Pakistani environment which make control over resources more effective than prediction for all kinds of firms. Also a cross sectional data doesn't capture the evolution in decision making that comes with maturing of the firm in a particular environment, this could vary from one firm to another (Brettel et al., 2012; Johansson \& McKelvie, 2012). Analyzing firms of different ages and sizes across sector could help in getting better results according to literature.

\section{CONCLUSION AND RECOMMENDATION}

With this present study, the aim was to advance the understanding of how the interplay of the various effectuation constructs influences the firm perceived financial performance and the level of innovation. The adoption of the effectual decision making can be beneficial for the entrepreneur and the venture in many ways as outlined in previous studies (Brettel et al, 2012; Read et al. 2009; Wiltbank et al. 2009). The study addressed a research gap as suggested by Davidsson et al. (2010) regarding the exploring of the relationship between effectuation, performance and innovation in nascent firms. The findings of this study suggest varying degrees of the benefits of the effectuation constructs with some having greater impact than others and some having none. However, the study reveals that two dimensions of effectuation (flexibility and pre-commitments) have a greater positive impact on both financial performance and the level of innovation used in the firm. With the overall 
model being only relatively strong there is still scope for many other dependent variables of the use of effectual logic.

The positive impact of effectuation on performance has already been established in previous studies conducted in the context of different countries and sectors (Johansson \& McKliev, 2012; Smolka, Verheul\& Lamp, 2015; Mthanti, 2012). All of these concluded that flexibility has a stronger impact on financial performance while this study adds pre commitments as being another important antecedent to mitigating risk and enhancing performance.

The uniform use and impact of effectuation on performance between both micro and small firms is contrary to existing literature and findings of Sarasvathy (2011), Dew, Read\& Sarasvathy (2006) and Politis \& Gabrielsson (2006). This could again be mainly due to the exclusion of larger firms in the sample.

None of the researches mentioned above explored the level of innovation as a dependent variable of the use of effectual decision making. This research found a positive and significant relationship between most of the effectual constructs and the level of process and service innovation used in the firm. Though the use of effectuation did not vary among the size of the firm but the micro firms were found to be much more flexible and innovative which can be attributed to the greater need of survival during the startup phase.

\section{LIMITATIONS AND FUTURE RESEARCH}

Despite the strength of the study and promising findings, there are certain limitations as well. Firstly the study was conducted in only one city of Pakistan: Karachi and hence many findings cannot be generalized. The data was mainly collected through questionnaires while other techniques like interviews, focus groups could be an implication for future research. The time constraints of the study led to limited variables being investigated while many could be explored in future research. Future studies could investigate the interrelationship between the use of causation and effectuation. Though few studies have been advanced in this direction but more work is needed to validate their claims. As the phenomenon of effectuation is relatively new in Pakistan, although being followed, there is a lot of scope for research in the various industries and sectors. The role of entrepreneurial education can also be explored on the type of decision making used as the emphasis of most business schools is on causal logic. Finally there is a need to distinguish the concept of effectuation from other techniques like bootstrapping (Bhide, 1991) and bricolage (Baker \& Nelson, 2005).

\section{REFERENCES}

Ansoff, H. I. (1991). Critique of Henry Mintzberg's 'The design school: reconsidering the basic premises of strategic management'. Strategic management journal, 12(6), 449461.

Brews, P. J., \& Hunt, M. R. (1999). Learning to plan and planning to learn: Resolving the planning school/learning school debate. Strategic Management Journal, 20(10), 889913.

Berends, H., Jelinek, M., Reymen, I., \& Stultiëns, R. (2014). Product Innovation Processes in Small Firms: Combining entrepreneurial effectuation and managerial causation. Journal of Product Innovation Management, 31(3), 616-635.

Brettel, M., Mauer, R., Engelen, A., \& Küpper, D. (2012). Corporate effectuation: Entrepreneurial action and its impact on $R \& D$ project performance. Journal of Business Venturing, 27(2), 167-184. 
Baker, T., \& Nelson, R. E. (2005). Creating something from nothing: Resource construction through entrepreneurial bricolage. Administrative science quarterly,50(3), 329-366.

Bhide, A. (1991). Bootstrap finance: the art of start-ups. Harvard business review, 70(6), 109117.

Dew, N., Read, S., Sarasvathy, S. D., \& Wiltbank, R. (2009). Effectual versus predictive logics in entrepreneurial decision-making: Differences between experts and novices. Journal of business venturing, 24(4), 287-309.

Chandler, G. N., DeTitenne, D. R., McKelvie, A., \& Mumford, T. V. (2011). Causation and effectuation processes: A validation study. Journal of business venturing, 26(3), 375390.

Fredrickson, J. W. (1984). The comprehensiveness of strategic decision processes: Extension, observations, future directions. Academy of Management journal, 27(3), 445-466.

Gabrielsson, J., \& Politis, D. (2011). Career motives and entrepreneurial decision-making: examining preferences for causal and effectual logics in the early stage of new ventures. Small Business Economics, 36(3), 281-298.

Garonne, C., Davidsson, P., \& Steffens, P. R. (2010). Do strategy choices matter for nascent firms? A study on effectuation and causation impacts on new ventures outcomes. Proceedings of the 7th AGSE International Entrepreneurship Research Exchange.

Harms, R., \& Schiele, H. (2012). Antecedents and consequences of effectuation and causation in the international new venture creation process. Journal of international entrepreneurship, 10(2), 95-116.

Kraaijenbrink, J., Ratinho, T., \& Groen, A. (2011). Planning effectual growth: a study of effectuations and causation in nascent firms.

Loch, C. H., Solt, M. E., \& Bailey, E. M. (2008). Diagnosing unforeseeable uncertainty in a new venture. Journal of product innovation management,25(1), 28-46.

Mintzberg, H. (1990). The design school: reconsidering the basic premises of strategic management. Strategic management journal, 11(3), 171-195.

McKelvie, A., DeTienne, D. R., \& Chandler, G. N. (2013). What is the appropriate dependent variable in Effectuation Research? Babson College Entrepreneurship Research Conference.

McKelvie, A., Haynie, J. M., \& Gustavsson, V. (2011). Unpacking the uncertainty construct: Implications for entrepreneurial action. Journal of Business Venturing, 26(3), 273292.

Perry, J. T., Chandler, G. N., \& Markova, G. (2012). Entrepreneurial effectuation: a review and suggestions for future research. Entrepreneurship Theory and Practice, 36(4), 837-861.

Politis, D., \& Gabrielsson, J. (2006). Entrepreneurial Decision Making: Examining Preferences for Casual and Effectual Reasoning in the New Venture Creation Process. Lund Institute of Economic Research, Lund University.

Porter, 1980. Porter M. E. Competitive strategy. New York: Free Press, 1980.

Read, S., Song, M., \& Smit, W. (2009). A meta-analytic review of effectuation and venture performance. Journal of Business Venturing, 24(6), 573-587.

Read, S., \& Sarasvathy, S. D. (2005). Knowing what to do and doing what you know: Effectuation as a form of entrepreneurial expertise. The Journal of Private Equity, 9(1), 45-62.

Sarasvathy, S. D. (2001). Causation and effectuation: Toward a theoretical shift from economic inevitability to entrepreneurial contingency. Academy of management Review, 26(2), 243- 263. 
Sarasvathy, S. D. (2001, August). Effectual reasoning in entrepreneurial decision making: existence and bounds. In Academy of management proceedings (Vol. 2001, No. 1, pp. D1-D6). Academy of Management.

Sarasvathy, S. D. (2009). Effectuation: Elements of entrepreneurial expertise. Edward Elgar Publishing.

Sarasvathy, S. D. (2003). Entrepreneurship as a science of the artificial. Journal of Economic Psychology, 24(2), 203-220.

Shane, S., \& Venkataraman, S. (2000). The promise of entrepreneurship as a field of research. Academy of management review, 25(1), 217-226.

Simon, M., Houghton, S. M., \& Aquino, K. (2000). Cognitive biases, risk perception, and venture formation: How individuals decide to start companies. Journal of business venturing, 15(2), 113-134.

Smolka.K.M., Verheul.I., Lamp.K.B. (2015). Successful Entrepreneurs do both: Effectuation and Causation and relation with Firm Performance. Academy of Management Annual Meeting 2015. Ottawa, Canada.

Venkataraman, S., \& Sarasvathy, S. D. (2001). Strategy and entrepreneurship: Outlines of an untold story.

Wiltbank, R., Dew, N., Read, S., \& Sarasvathy, S. D. (2006). What to do next? The case for non- predictive strategy. Strategic management journal, 27(10), 981-998. 